\section{Abstract}

The importance of volunteers within the fire service in most countries is unquestionable. However, the retention of volunteers is problematic and finding ways to retain experienced and qualified volunteers is becoming increasingly important. While previous international research has focused on volunteer retention and understanding why volunteers leave, very little is known about 'boomerang' volunteers: volunteers who return to the service after a break. These 'boomerangs' are a valuable staffing resource, as they tend to require less socialisation, onboarding and training. The latter is particularly relevant for the fire service, as the resources required to train and develop the necessary skills are significant. This study investigated volunteers in the Finnish Fire Service who have taken a break from the service and returned. Similar to Australia and New Zealand, Finland's emergency services are highly reliant on volunteers, particularly in rural areas. This research examined the reasons why breaks were taken and what volunteers experienced most helpful on their return.

Drawing on these findings, practical recommendations are made for fire service organisations for effective volunteer practices that take boomerang behaviour into account.

\title{
Boomerang volunteers in the Finnish Fire Service
}

\section{Peer Reviewed}

\section{Associate Professor \\ Sanna Malinen ${ }^{1}$ \\ Dr Puck Algera ${ }^{1}$ \\ Dr Teija Mankkinen²}

1. University of Canterbury, Christchurch, New Zealand.

2. Department for Rescue Services, Ministry of Interior, Helsinki, Finland.

\section{SUBMITTED}

3 March 202

\section{ACCEPTED}

18 May 2021

\section{DOI}

www.doi.org/10.47389/36.4.50

\section{(c) 1 (1) (9)}

(C) 2021 by the authors. License Australian Institute for Disaster Resilience, Melbourne, Australia. This s an open access article distributed under the terms and conditions of the Creative Commons Attribution (CC BY) license (https:// creativecommons.org/ licenses/by/4.0/).

\section{Introduction}

The backbone of the emergency fire services globally, particularly in rural areas, consists of trained volunteers rather than paid staff (Degel et al. 2014). These trained volunteers and the resources needed to develop the necessary skills are significant. However, the retention of volunteers is problematic and volunteer fire service numbers have been declining in Australia and elsewhere (Corydon Consultants 2006, Cowlishaw et al. 2014, West \& Murphy 2016). As the challenges of recruiting and retaining a sufficient number of fire service volunteers intensifies, finding ways to hold on to experienced and qualified volunteers is increasingly important (Beatson \& McLennan 2005).

While international research considered volunteer retention and reasons why volunteers leave, there is little about returning or 'boomerang' fire service volunteers. The lacuna in the volunteer literature is somewhat surprising given that 'returning volunteers may ... contribute to the effectiveness of a nonprofit by reducing the costs associated with the screening and training of new volunteers' (Lee, Won \& Bang 2014, p.230). Therefore, this research examined whether and why volunteers in the fire service take breaks and importantly, what they found to be helpful (or challenging) on their return to the service.

The study was situated in Finland, where the reliance on emergency services volunteers is considerable. Similar to Australia and New Zealand, Finland has significant rural areas that are entirely reliant on volunteer fire brigades.

\section{Breaks and returning from a break}

Much research has focused on the retention of volunteers and reasons why volunteers leave (e.g. Catino 2015, Cote et al. 2014, Smith 2014). In the general volunteering literature, research has investigated returning episodic volunteers: volunteers who engage in short-term volunteering assignments, such as specific events or projects (Hustinx \& Lammertyn 2003). These studies note that 'little is known about ... what needs to be done in order to successfully 'bounce-back' or return a volunteer for further volunteering tasks' (Bryen \& Madden 2006, p.1). Further, Bryen and Madden (2006) found that episodic volunteers were more likely to return if their original motivation to volunteer was met during the initial volunteering experience. However, it has also been noted that 'the results may not apply to other volunteering settings that is, regular volunteering' 
(Lee, Won \& Bang 2014, p.238). Given the scarcity of literature on boomerang volunteers, insights can be found in employee literature.

Human resources (HR) practices recognise the existence of 'boomerangs' or 'rehires' (Snyder \& Stewart 2015). The concept of boomerangs describes employees who return to a former workplace after having left (Apy \& Ryckman 2014). Boomerangs are a potentially valuable staffing resource (Apy \& Ryckman 2014, Shipp et al. 2014) and boomerang recruitment is a cost-effective and successful recruitment strategy (Hart 2009). Not only are boomerangs a 'known quantity', but they tend to assimilate more easily into the organisation's culture; understand policies and practices; require less socialisation, training and onboarding and are generally more productive (Hart 2009, Shipp et al. 2014).

Shipp and co-authors (2014) investigated the differences between boomerangs (employees who quit and later return) and alumni (employees who quit but do not return) and found that the groups 'have different perspectives on their employment experiences and thus, different reasons for (and risks of) leaving, even after controlling for alternative explanations such as demographics or performance concerns' (Shipp et al. 2014, p.448). Building on work by Lee and Mitchell (1994), they identified different decision paths for employees leaving their job, which 'summarize how employees interpret their work environments; how they identify decision options; and how they enact responses' (Lee \& Mitchell 1994, p.60). The authors argue that the different characteristics of these paths offers clues about who will return and who will not. For instance, they found that boomerangs were more likely to be classified as 'Path 1 ' leavers than alumni. Employees on Path 1 experience a shock ${ }^{1}$ that is combined with the existence of a plan, such as when an employee becomes pregnant and chooses to leave employment. Other examples are spousal relocation or a change in marital status (Shipp et al. 2014). A noteworthy characteristic of leavers on Path 1 is that the shock itself results in the decision to leave, but this happens with little deliberation and minimal evaluation of the job experience or satisfaction (Holtom et al. 2005, Mitchell \& Lee 2001, Shipp et al. 2014). As these shocks may be unavoidable and because plans to leave are not related to dissatisfaction with the job or the company, these leavers may be open to returning to the organisation at a later stage (Shipp et al. 2014). So rather than ignoring Path 1 leavers because they represent unavoidable turnover, organisations should be aware of the potential that leavers may eventually return. Shipp and colleagues (2014) also found that volunteers leaving for reasons related to dissatisfaction are more common for alumni than boomerangs. The research suggests that boomerangs quit earlier than alumni in their original tenure, 'paradoxically suggesting that employees who quit earlier may be the very employees who will return in the future' (Shipp et al. 2014, p.421).

Due to the potential importance of boomerang volunteers in the fire service, this study investigates whether volunteers in the Finnish Fire Service took breaks from their service, the reasons for these breaks and what hindered or helped their return to the service. Whether breaks were preventable by the fire service was also considered.

\section{Method}

\section{Participants and procedure}

A nationwide survey on fire service volunteering in Finland was conducted in 2012 as part of a larger research project on volunteer firefighter attitudes and motivations. A link to an online survey was sent to all Finnish volunteer fire brigades and was distributed to their volunteers. Participation in the survey was voluntary.

The survey included 4 questions relevant to this paper. Participants were asked whether they had taken a break from their fire service duties (yes/no), and if so, how many breaks they had taken (number and length recorded). They were also asked to describe the reasons for taking the break and what made their return easy or difficult (open-ended questions).

A total of 942 participants started the survey with 762 (81\%) completing the section relevant to taking breaks. Of the full sample, $81.7 \%$ of participants identified as male and participants were spread across all age groups. Almost a quarter of the participants (24.4\%) had been involved with the fire brigade for over 20 years, whereas only $2.5 \%$ were new recruits (less than 1 year).

The number of breaks and the length of each break were recorded and descriptive statistics were calculated. Responses to the open-ended questions were coded using thematic analysis. The number of participants who were coded as mentioning a theme was calculated (e.g. reason for taking a break was a move to another location). This provided quantitative data on the reasons why breaks were taken and what may have made a return to the service easy or difficult.

The research was reviewed and approved by the University of Canterbury Human Ethics Committee [HEC 2011/137].

\section{Findings}

\section{Reasons for taking a break}

Out of the 762 participants who responded to this question, 31\% $(n=236)$ had taken at least one break from the fire service. Males and females had similar rates of break taking (31.7\% males, $28 \%$ females had taken a break ${ }^{2}$ ) and the age distribution of break takers was similar to those who had not taken a break. Of the participants who had taken a break, $17.3 \%$ had taken one break, $4.2 \%$ had taken 2 breaks and $2.4 \%$ had taken 3 breaks. The average time for a break was 2 years $(S D=3.10)$, ranging from a few weeks to almost 30 years.

Table 1 shows the reasons for taking a break and the frequency that reasons were mentioned, as well as the analysis of whether the break may have been prevented by the fire service.

The reasons for taking breaks were varied, although consistent themes emerged. The most commonly cited reason for taking a break was moving to another area (26.3\%). The reasons for

\footnotetext{
1. A 'jarring event that initiates the psychological analyses involved in quitting a job' (Lee et al. 1999, p.451)

2. This difference is not statistically significant.
} 
the move varied, but they were commonly related to work and study. The second most common reason for taking a break was work and study and school commitments (17.2\%). Participants reported that they perceived work or educational commitments as high, rather than high demands from the fire service. Military service was also mentioned (15.1\%) as there is mandatory conscription for men in Finland. These reasons were coded as unpreventable by the fire service.

The reasons why volunteers took a break did not relate to their length of time in the fire service (i.e. volunteering tenure). The difference in the length of the break taken depended on the reason for the break $(F(10,204)=2.10, p=0.026))$. Post hoc analyses revealed that breaks due to unsatisfactory activities were longer ( $M=5.40$ years, $S D=5.50)$ than when taking a break for most other reasons:

- negative atmosphere, $M=2.10$ years, $S D=2.92$

- lack of energy/motivation, $M=1.49$ years, $S D=1.86$

- health concerns, $M=0.61$ years, $S D=0.73$

- work/school-related activities, $M=1.99$ years, $S D=2.14$

- military service, $M=0.91$ years, $S D=0.20$

- other hobbies, $M=1.37$ years, $S D=1.18$.

In addition, moving to another location resulted in longer breaks $(M=2.98$ years, $S D=4.53)$ than when taking a break due to health concerns $(M=0.61$ years, $S D=0.73)$ or military service $(M=0.91$ years, $S D=0.20)$.

\section{Return to service}

To understand what makes the return to service easy or challenging, participants responded to an open-ended question about the factors that made the return easy or difficult.
The responses were coded into themes and the number of participants mentioning each theme was calculated.

The most frequently stated factor for making a return to the service easier was social factors (63\% of participants who responded to this question). That is, volunteers rated having familiar, friendly faces to return to as important: 'familiar faces', 'familiar team who welcomed me back'. In addition, a positive climate in the fire service was considered valuable: 'good team spirit at the brigade'.

Another factor mentioned by $12.3 \%$ of participants included being familiar with the role requirements, that is, being familiar with the routine and skills required: 'basic tasks remained the same', 'I knew the basics', 'familiar tasks'.

Some suggestions offered by participants that would make a return easier were keeping in touch with the brigade during the break and having a brief training session on return to make sure skills are up to date.

When asked what made the return to the fire service challenging, the most frequently cited response (29.3\% of participants who responded to this question) was that 'nothing' was perceived as difficult in returning. This may indicate that those volunteers who decided to return to the fire service after a while away are doing so with very few barriers. It is important to note however, that our sample included only volunteers who had actually returned after a break.

The second most common challenge (22.6\% participants who responded to this question) was that some skills had been forgotten during the break: 'I'd forgotten many things during the break', 'felt like I was left behind with training'.

Finally, $19.5 \%$ of respondents found certain social factors to be challenging on their return, such as changed personnel,

Table 1: Reasons for taking a break in order of frequency.

\begin{tabular}{|c|c|c|c|c|}
\hline $\begin{array}{l}\text { Rank } \\
\text { order }\end{array}$ & Reason for taking a break & Frequency & $\begin{array}{l}\text { Percentage of those who } \\
\text { have taken a break }\end{array}$ & $\begin{array}{l}\text { Preventable vs. not by fire service } \\
\text { (PREV/not PREV) }\end{array}$ \\
\hline 1 & Move to another city/region & 61 & 26.3 & not PREV \\
\hline 2 & Work/school-related activities & 40 & 17.2 & mostly not PREV \\
\hline 3 & Military service & 35 & 15.1 & not PREV \\
\hline 4 & Health concerns & 18 & 7.8 & not PREV \\
\hline 5 & Other hobbies & 17 & 7.3 & some possibly PREV \\
\hline 6 & Family commitments & 17 & 7.3 & some possibly PREV \\
\hline 7 & Lack of energy/motivation & 13 & 5.6 & PREV \\
\hline 8 & Negative atmosphere in department & 12 & 5.2 & PREV \\
\hline 9 & Other & 12 & 5.2 & \\
\hline 10 & No satisfactory activities & 5 & 2.2 & PREV \\
\hline 11 & Lack of time & 2 & 0.9 & some possibly PREV \\
\hline
\end{tabular}


" RESEARCH

personality clashes with others or feeling a psychological distance from team members: 'chemistry between people', 'getting back 'in' to the group', 'poor team spirit'.

\section{Discussion}

These findings show that taking breaks is a not an infrequent occurrence within the volunteer fire service, with close to a third of the sample confirming they had done so. This research suggests that understanding volunteer leaving and boomerang behaviour is an important part of the volunteer recruitment and retention practice.

The majority of volunteers take breaks for reasons that are unrelated to the volunteer experience or the fire service itself. As suggested by Shipp and co-authors' (2014) work with paid employees, this is the group that is most likely to 'boomerang' (i.e. Path 1 leavers). The most frequently mentioned reasons like moving to another location, study or work commitments or military service are difficult to prevent from an organisation's perspective. These reasons are largely unavoidable and are unrelated to dissatisfaction with volunteering for the organisation, and importantly, these leavers may return to the service at some later time. Health issues and family commitments were also mentioned and as these causes are unrelated to the volunteer experience, they are largely unpreventable by the service. However, there are some actions the fire service can take to help make balancing family commitments and health issues and volunteering easier to achieve.

Overall, the findings suggest that some participants took a break because they were dissatisfied with volunteering or the fire service. It is noteworthy that those (although only a few) volunteers who took a break because of a lack of satisfactory activities took significantly longer breaks as compared with most other reasons for break taking. The importance of providing interesting activities for fire brigade volunteers has been noted in relation to volunteer barriers (Malinen \& Mankkinen 2018). Importantly, the present study did not collect data from those volunteers who had left and did not return. It is quite possible that those volunteers who experience high dissatisfaction with the fire brigade may not return from their break or simply leave the service. Our finding that most breaks are taken for unpreventable reasons should be interpreted with caution, and promoting a psychologically safe and positive culture in the fire service should remain a priority for service leadership. We also recommend research on those who have taken a break from volunteering and decided not to return.

The study revealed some key elements that make returning to volunteering easier. These include social factors, such as familiar people and friends, a positive climate and familiarity with the role requirements. Importantly, these are factors that the fire brigade has influence over.

\section{Implications for fire service}

An understanding of the different reasons why volunteers take breaks can guide the objective and the nature of the HR approach to volunteers and can inform leadership practices. Different reasons require tailored retention practices if the fire service, and volunteer organisations generally, want to maximise retention and support 'boomerang' behaviour in volunteers.

For instance, for volunteers who leave for unpreventable reasons, the objective from the organisation's perspective is not necessarily to prevent these breaks from happening, but to set the stage for returning. The fire service can pre-emptively discuss different scenarios of returning with those planning on taking a break. For example, when a volunteer moves to another location, it may be helpful for the service to provide details of fire departments the volunteer could join at the new location, and departments in the new location could be contacted and a meet and greet could be facilitated.

To set the stage for an easy return, the fire department can ensure that the volunteer remains socially connected to the service by regular communications and invitations to social events at the station. Some participants expressed that they would have benefited from refresher courses once they returned to the service. If this is not routine practice, this is something that fire services may consider implementing to ensure volunteers feel that they possess the knowledge and skills necessary. This suggestion is supported by Lee, Won and Bang (2014), who found proficiency and familiarity with the role requirements help ease re-entry.

Other reasons for taking a break, such as health issues and family commitments, may not be preventable by organisations, but there may be actions that can be taken to ensure an easy return or to reduce the length and number of breaks. For instance, the HR practice can focus on helping volunteers with balancing family commitments/health challenges and volunteering. Indeed, previous research found that volunteers' child care responsibilities constitutes a significant barrier for volunteering (McLennan et al. 2007, Malinen \& Mankkinen 2018). Although the fire service may not have direct influence over such a barrier, it is important to be aware of the competing commitments of volunteers with care responsibilities and, when possible, offer flexible types of volunteering opportunities. Fundraising tasks, for example, could be one such area. Similarly, for those with physical health challenges, the service could arrange volunteers to be engaged in less physically demanding duties.

While in the minority, various reasons for taking a break were also reported where the fire service can play a role in preventing absences. This includes reducing any negative atmosphere or lack of interesting training activities. These breaks may be preventable through leadership practices or culture changes that address the atmosphere and relationships in the service. The HR practice could, for example, focus on monitoring volunteer satisfaction. Regular, anonymous surveys that investigate volunteer motivation and enthusiasm, as well as the perception of the work culture highlight issues that can then be addressed.

\section{Conclusion}

This study took a subset of questions from a larger survey of fire services volunteers in Finland to draw out factors about why volunteers leave and return. The aim was to identify why volunteers took breaks and what facilitated their return, to assist in retention and attraction policies. This study can 
inform emergency services organisations as well as volunteer organisations in other sectors on volunteer management and offers suggestions as to how to optimise return and retention of highly-skilled volunteers.

While volunteers taking breaks is often unpreventable, there are various HR-related actions that can encourage volunteers to return, increasing the likelihood that skills are retained. These findings related to fire services but could also extend to any organisation wanting to attract past volunteers back to the organisation.

\section{References}

Apy FA \& Ryckman J 2014, Boomerang hiring: Would you rehire a past employee?, Employment Relations Today, vol. 41, no. 3, pp.13-19.

Beatson R \& McLennan J 2005, Australia's women volunteer fire fighters: A literature review and research agenda, Australian Journal on Volunteering, vol. 10, no. 2, pp.18-27.

Bryen LM \& Madden KM 2006, Bounce-Back of episodic volunteers: What makes episodic volunteers return?, Working Paper No. CPNS 32, Centre of Philanthropy and Nonprofit Studies Queensland University of Technology Brisbane, Australia. At: https://eprints.qut.edu.au/4450/1/CPNS_Working_Paper_No_32. pdf [October 2020].

Catino JE 2015, An examination of factors influencing retention of volunteer firefighters in the commonwealth of Pennsylvania, The Pennsylvania State University, USA.

Cote M, Hasskamp B, Chevuru P \& Verma M 2014, Empty boots, quiet sirens: The state of non-career firefighting in Minnesota: $A$ report to the Minnesota State Fire Chiefs Association, Humphrey School of Public Affairs. At: https://conservancy.umn.edu/ handle/11299/164931 [October 2020].

Corydon Consultants 2008, Training for rural firefighters: Motivators and impediments, New Zealand Fire Service Research Reports. At: https://silo.tips/queue/training-for-rural-firefightersmotivators-and-impediments?\&queue_id $=-1 \& v=1614292961 \& u=$ MTE5LjlyNC44MS450A== [January 2021].

Cowlishaw S, Birch A, McLennan J \& Hayes P 2014, Antecedents and outcomes of volunteer work-family conflict and facilitation in Australia, Applied Psychology, vol. 63, no. 1, pp.168-189.

Degel D, Wiesche L, Rachuba S \& Werners B 2014, Reorganizing an existing volunteer fire station network in Germany, SocioEconomic Planning Sciences, vol. 48, no. 2, pp.149-157.

Hart KA 2009, Boomerang recruitment: Bridging the gap, Nursing Economics, vol. 27, no. 1, pp.56-63.

Holtom BC, Mitchell TR, Lee TW \& Inderrieden EJ 2005, Shocks as causes of turnover: What they are and how organizations can manage them, Human Resource Management, vol. 44, no. 3, pp.337-352.

Hustinx L \& Lammertyn F 2003, Collective and Reflexive Styles of Volunteering: A Sociological Modernization Perspective, Voluntas: International Journal of Voluntary and Nonprofit Organizations, vol. 14, no. 2, pp.67-187.
Lee TW, Mitchell TR, Holtom BC, McDaneil LS \& Hill JW 1999, The Unfolding Model of Voluntary Turnover: A Replication and Extension, Academy of Management Journal, vol. 42, no. 4, pp.450-462.

Lee Y-j, Won D \& Bang H 2014, Why do event volunteers return? Theory of planned behavior, International Review on Public and Nonprofit Marketing, vol. 11, no. 3, pp.229-241.

Lee TW \& Mitchell TR 1994, An alternative approach: the unfolding model of voluntary employee turnover, The Academy of Management Review, vol. 19, no. 1, pp.51-89.

Malinen SK \& Mankkinen T 2018, Finnish firefighters' barriers to volunteering, Nonprofit and Voluntary Sector Quarterly, vol 47, no. 3, pp.604-622.

McLennan J, Birch A, Beatson R \& Cowlishaw S 2007, Factors Impacting on Recruiting and Retaining Australia's Volunteer Firefighters: Some Research Evidence, Australian Journal on Volunteering, vol. 12, no. 2, pp.59-69.

Mitchell TR \& Lee TW 2001, The unfolding model of voluntary turnover and job embeddedness: Foundations for a comprehensive theory of attachment' Research in Organizational Behavior, vol. 23, pp.189-246.

Shipp AJ, Furst-Holloway S, Harris TB \& Rosen B 2014, Gone Today but here Tomorrow: Extending the Unfolding Model of Turnover to Consider Boomerang Employees, Personnel Psychology, vol. 67, no. 2, pp.421-462.

Smith MR 2014, Retention of firefighters in volunteer fire departments in suburban Nebraska, Capella University, ProQuest Dissertations Publishing.

Snyder DG \& Stewart VR 2015, Organizational reattachment: Quantifying the benefits of boomerang employees, Academy of Management Proceedings, vol. 2015, no. 1, p.17837.

West D \& Murphy P 2016, Managerial and leadership implications of the retained duty system in English fire and rescue services: An exploratory study, International Journal of Emergency Services, vol. 5, no. 2, pp.184-198.

\section{About the authors}

Professor Sanna Malinen is an Associate Professor of Organisational Behaviour and HRM at the University of Canterbury, New Zealand. Her background is in organisational psychology and she researches in the areas of workplace resilience, employee wellbeing and disaster management.

Dr Puck Algera is a strategist and researcher whose work focuses on humanising organisations, social impact management and the future of work. She holds a Master's in Business Economics from the Rijksuniversiteit Groningen and a PhD in Management from the University of Canterbury, New Zealand.

Dr Teija Mankkinen is a Senior Specialist at Finland's Ministry of Interior, Department for Rescue Services and was previously a research manager at the Finnish National Rescue Association, Finland. 